\title{
Evaluate College Students' Learning Situation Based on Test Results
}

\author{
Yaming Ren \\ School of Mechanical and Control Engineering, Guilin University of Technology, Guilin, China \\ Email: renyaming1981@gmail.com
}

How to cite this paper: Ren, Y.M. (2019) Evaluate College Students' Learning Situation Based on Test Results. Open Access Library Journal, 6: e5542. https://doi.org/10.4236/oalib.1105542

Received: June 13, 2019

Accepted: June 22, 2019

Published: June 25, 2019

Copyright $\odot 2019$ by author(s) and Open Access Library Inc.

This work is licensed under the Creative Commons Attribution International License (CC BY 4.0).

http://creativecommons.org/licenses/by/4.0/

(c) (i) Open Access

\begin{abstract}
The purpose of college education is to cultivate students' self-learning ability to analyze and solve problems. In this paper, we use the method of mathematics to express the information of students' examination results intuitively in the form of graphs. Using the visual characteristics of the graph, the students' grasp of knowledge points is analyzed. The analysis results show that; students have a good grasp of basic concepts and definitions, and the flexible use of knowledge to solve practical problems is associated with a low scoring rate. Finally, we suggest strengthening the practical education part of the curriculum.
\end{abstract}

\section{Subject Areas}

Education

\section{Keywords}

Histogram, Probability Density Function, Practice

\section{Introduction}

In the 1990s, the American educational circles put forward the return to engineering; there is the classic concept of big engineering and the concept of CDIO (conceive, design, implement and operate) [1] [2]. The core of the concept of big engineering does not mean the scale or influence of the project, but should combine a series of non-technical factors such as economy, culture and morality with engineering practice. The CDIO concept emphasizes that engineers' technical level, communication ability and overall view are always acquired in real engineering practice [3] [4], and the concept of CDIP has been widely used in the teaching process of various subjects [5] [6] [7] [8]. As a whole, different theories emphasize the importance of practice. 
Foundation of power system engineering is a basic major course of automation, which is closely related to the production process and has a strong engineering application. In traditional theoretical teaching activities, university teachers first teach basic theories and concepts to students in the form of PPT, and apply the knowledge taught to solve problems. Finally, university teachers summarize the course and draw the key points. According to the author's actual teaching process, it is found that the process of power system engineering foundation teaching is often troubled by the following problems: firstly, the teaching content of foundation of power system engineering includes a wide range of contents such as power system analysis, electric elements of power plants and power system relay protection. Secondly, the foundation of power system engineering is practical. Specifically, the contents involved in foundation of power system engineering come from the actual engineering objects, and the content of the course must be consistent with the actual engineering.

It is a fact that different teaching methods and teaching emphasis will affect students' achievement. Some scholars design unique teaching processes based on goals in order to achieve their own teaching objectives. Cordero, Jose $\mathrm{M}$ and Gil-Izquierdo, María take advantage of TALIS-PISA-link to study the impact of different teaching methods on achievement [9]. At the same time, we can consider from the opposite process; if we analyze students' performance and find out the shortcomings, then we can design the teaching process for the students' shortcomings. John Jerrim, Mary Oliver and Sam Sims point out that students can obtain corresponding scientific knowledge from their own experiments and practices, which are often difficult to be taught by teachers in the class [10]. Therefore, in this paper, we propose to increase students' practice part, so that students can get practical engineering experience that cannot be obtained in the classroom. In this paper, through the analysis of students' final examination results, we can judge students' mastery of the knowledge structure of this course, so as to facilitate teachers to make corresponding improvements in teaching activities in the future.

\section{The Test Design of the Foundation of Power System Engineering}

For the test design of the foundation of power system engineering, we must first ensure that students have a good grasp of basic theoretical knowledge, so the basic theory should take a large proportion in the test design. At the same time, considering the foundation of power system engineering and practical engineering application are closely connected, it is necessary to verify students' handling of the actual situation, especially to verify students' flexible application of the knowledge they have learned, we should ensure that the actual operation and calculation of the power system occupies a certain proportion in the test paper. To sum up, the test design of the foundation of power system engineering is shown in Table 1. 
Table 1. The test design of the foundation of power system engineering.

\begin{tabular}{ccc}
\hline Question types & Score & Assessment knowledge \\
\hline $\begin{array}{c}\text { Fill-in-the-blank } \\
\text { Single choice }\end{array}$ & 10 & A direct examination of concepts and definitions \\
Short answer & 30 & Practical application of concepts and definitions \\
Operation & 10 & Esplaing of knowledge points to achieve on-site operation \\
Calculations & 30 & Analyze and solve problems \\
\hline
\end{tabular}

According to the description in Table 1, it can be seen that the fill-in-the-blank, single choice and short answer questions only require students to master the basic knowledge of power system, and the corresponding difficulty is relatively low. The total score was set to 60 . In particular, for the fill-in-the-blank, there are ten questions, one blank for each question, and the total score is ten. For the Single choice, there are ten questions, one choice for each question, and the total score is twenty. For the Short answer, there are 5 questions, and the total score is thirty.

For the question types of operation and calculations, the purpose of assessment lies in the flexible use of knowledge points, requiring students to have the ability to analyze and solve problems. These types of question are worth 40 points. Take electric switching operation as an example. The basic principle is simple: when you disconnect the circuit, first disconnect the circuit breaker, and then disconnect the disconnecting switches on both sides of the circuit breaker. When closing the circuit, first close the disconnecting switches on both sides of the circuit breaker, and then close the circuit breaker. In the actual operation, there are many circuit breakers and disconnecting switches, how to carry out the operation according to the standard is what we want to exam.

The test design of the foundation of power system engineering, on the one hand, can ensure that students can make more questions and pass the examination. On the other hand, students who want to get high marks must review carefully after class and understand essentially what is taught in the course. Teachers can judge students' mastery of the course by analyzing students' scores in operation and calculations.

\section{Results and Discussion}

In this paper, we selected the test scores, in the course of foundation of power system engineering, of 39 students from class 16-1, automation major, school of mechanical and control engineering, Guilin University of Technology, as the sample.

The information shown in Figure 1 is the histogram of test scores of 39 students and the corresponding probability density function of normal distribution. According to the information in Figure 1, it can be known that the distribution of students' scores basically conforms to the characteristics of normal probability 


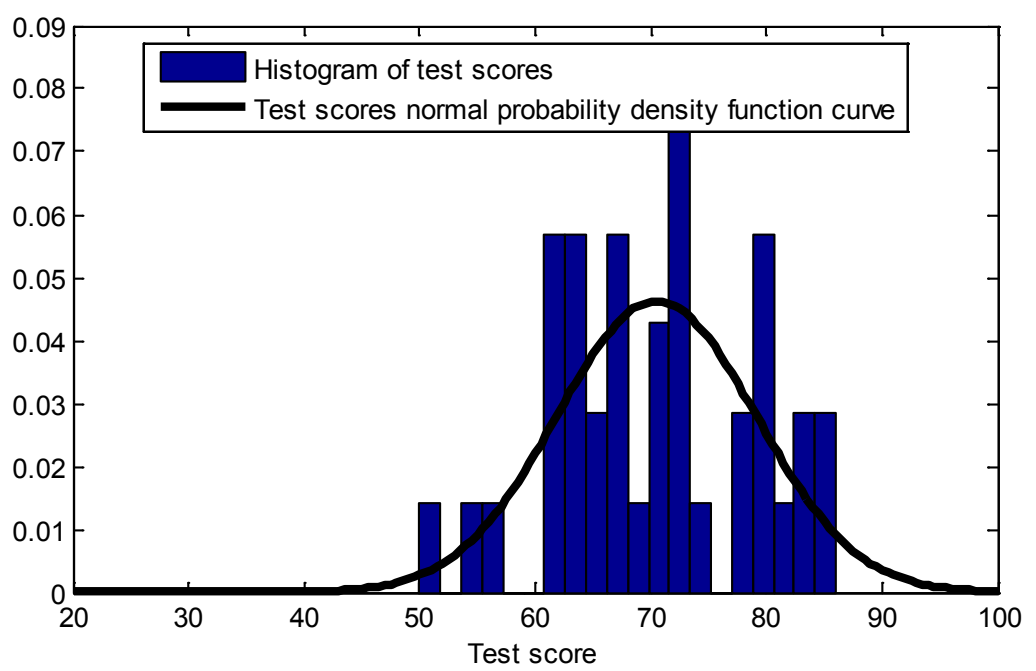

Figure 1. Test results histogram and the corresponding normal distribution probability density function.

distribution. Further analysis shows that students' scores are mainly in the range of $65-85$, that means most students pass the exam.

However, in this paper, we want to find out the weak links of students, we need to further analysis of students' performance. For this purpose, we divide the paper into two parts. In the first part, there are fill-in questions, choice questions and short answer questions, the key points are students' memory and application of basic concepts. The second part includes operational and computational questions, the focuses on the flexible use of knowledge or the ability to analyze and solve questions.

By observing the changes of the curve in Figure 2, it can be obviously found that the histogram basically coincides with the normal probability density curve. The first part of the exam results are mainly between 45 and 60, considering that the total score for the first part is 60 , it is clear that the scoring rate of the first part of students mainly focuses on $75 \%-90 \%$. For this reason, students scored well in the first part, indicating that students had a good grasp of the basic concepts and definitions of power system.

Specifically speaking, for the 39 students, the number of students who scored between 10 and 29 was 35 , considering that the total score for the second part is 40 , it is clear that the scoring rate of the second part of students mainly focuses on $25 \%-70 \%$. Compared with the scoring rate of the first part of the test paper, the scoring rate of the second part of the test paper is low. That is to say, most students in the second part of the exam, the score did not reach the pass line. In fact, the result is not surprising. Because the second part of the examination paper is a student's ability to use knowledge flexibly and the ability to analyze problems. In China, college education tends to focus on the theoretical teaching in the classroom, which is insufficient to cultivate students' practical engineering ability.

The information shown in Figure 3 is the histogram of students' scores in the 


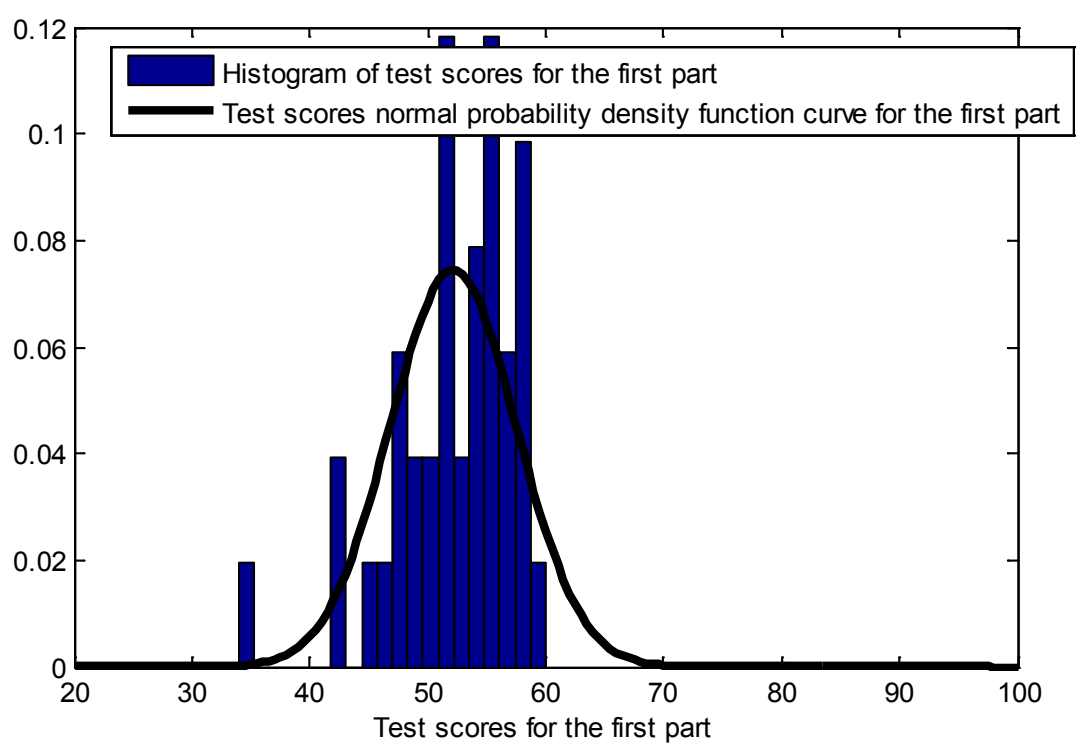

Figure 2. Test results histogram and the corresponding normal distribution probability density function for the first part (fill-in questions, choice questions and short answer questions).

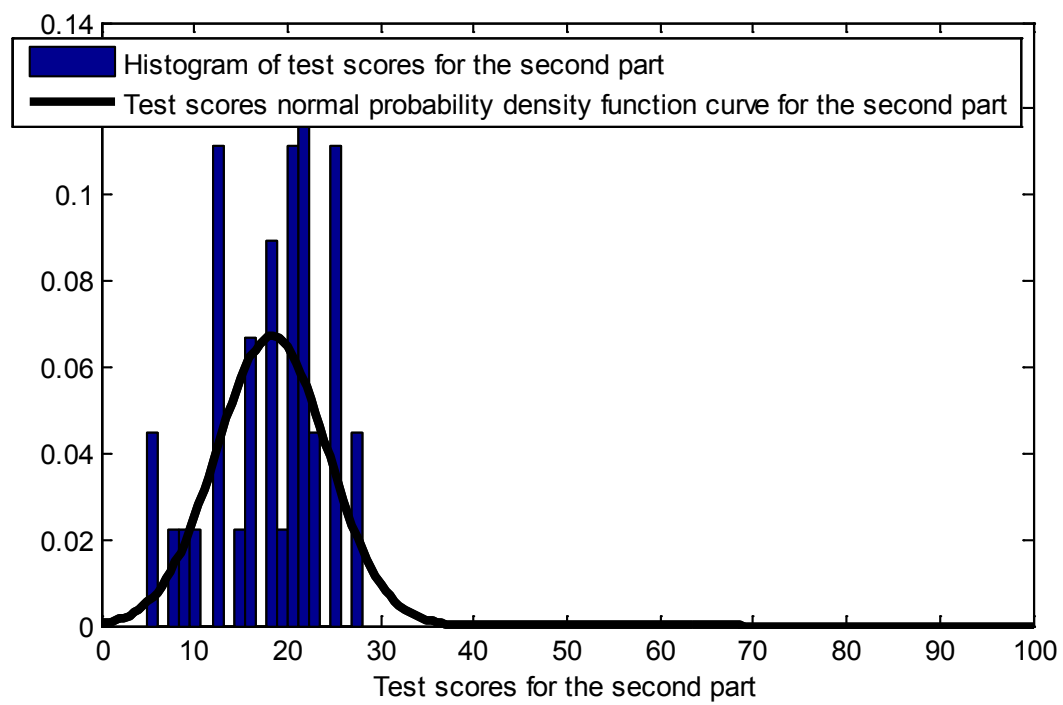

Figure 3. Test results histogram and the corresponding normal distribution probability density function for the second part (operational and computational questions).

second part of the paper (operational and computational questions) and the corresponding normal probability density function.

We have made this clear in the first section of this paper: different theories emphasize the importance of practice. For engineering majors, after graduation, students have to face specific project. No one can become a good engineer by rote, the right way to be a good engineer is to have the ability to analyze and solve problems through the flexible use of the theoretical knowledge learned and this is what we want students to learn in college.

According to the examination result, the engineering practice part should be 
strengthened in the teaching activity of power system engineering foundation and specific measures are shown below.

1) Add practice section to ensure that each student has 6 class hours of practical operation. The author hopes to strengthen students' cognition and understanding of practical engineering by adding practical class hours. The specific contents are: switching operation and power system short circuit test. This is just the author's idea, and the specific effect needs to be verified by specific actual data. The author will collect and analyze the data in the next stage.

2) Make strict assessment standards, requiring students to demonstrate on the spot.

3) Submit a complete practice report, including the analysis and solution sections of the problem.

\section{Conclusion}

The purpose of college education is to cultivate students' self-learning ability to analyze and solve problems, not just rote learning. For engineering students, it is essential to combine theory with practice if they want to be an excellent engineer. In this paper, we analyze students' mastery of knowledge from their examination results; it is found that students are weak in the practical application of theoretical knowledge. Finally, aiming at this problem, we give the methods to enhance students' practical ability in the future teaching activities. In this paper, we only analyze the results of students. In practice, student achievement is often related to many factors, such as academic attendance and time spent after class. The author will consider more factors in the next work.

\section{Acknowledgements}

The publication was prepared with the financial support of Teaching Reform Project of Guilin University of Technology: Application and practice of CDIO teaching method in the course of foundation of power system engineering (2019B16).

\section{Conflicts of Interest}

The author declares no conflicts of interest regarding the publication of this paper.

\section{References}

[1] Zhong, S.Y., Chen, Y.Z., Li, R.Y., et al. (2014) Application of CDIO Idea in Engineering Training. Advanced Materials Research, 3140, 1479-1482. https://doi.org/10.4028/www.scientific.net/AMR.915-916.1479

[2] Gunnarsson, S. (2017) Automatic Control Education in a CDIO Perspective. IFAC-PapersOnLine, 50, 325-330. https://doi.org/10.1016/j.procir.2018.03.277

[3] Song, D. (2018) Comparison of CDIO and Chinese Engineering Education Accreditation for Animation Specialty of TUST. Procedia Computer Science, 131, 765-770. https://doi.org/10.1016/j.procs.2018.04.322 
[4] Chuchalin, A., Malmqvist, J. and Tayurskaya, M. (2016) Professional Development of Russian HEIs' Management and Faculty in CDIO Standards Application. European Journal of Engineering Education, 41, 426-437. https://doi.org/10.1080/03043797.2015.1085837

[5] Yan, H. and Hu, H.Y. (2014) Study on CDIO Talents Training System Based on the Internet of Things and Cloud Computing in Big Data Era. Advanced Materials Research, 989-994, 4949-4952.

https://doi.org/10.4028/www.scientific.net/AMR.989-994.4949

[6] Wang, Y., Zheng, S., Zhang, M., et al. (2014) Mode Reform of Sensor Courses Teaching in Civil Engineering Based on CDIO Education Concept. Sensors \& Transducers, 173, 297-304.

[7] Hu, L., Li, Y., et al. (2013) The Progress of CDIO Engineering Education Reform in Several China Universities: A Review. Procedia-Social and Behavioral Sciences, 93, 381-385. https://doi.org/10.1016/j.sbspro.2013.09.207

[8] Lu, J., Yu, S., Jin, Z. and Wang, X. (2012) The Application of CDIO Standard and Computer Assist Instruction in the Design Course of Plain Fabric. International Journal of Education and Management Engineering, 2, 39-44. https://doi.org/10.5815/ijeme.2012.04.07

[9] Cordero, J.M. and Gil-Izquierdo, M. (2018) The Effect of Teaching Strategies on Student Achievement: An Analysis Using TALIS-PISA-Link. Journal of Policy Modeling, 40, 1313-1331. https://doi.org/10.1016/j.jpolmod.2018.04.003

[10] Jerrim, J., Oliver, M. and Sims, S. (2019) The Relationship between Inquiry-Based Teaching and Students' Achievement. New Evidence from a Longitudinal PISA Study in England. Learning and Instruction, 61, 35-44.

https://doi.org/10.1016/j.learninstruc.2018.12.004 